\title{
Obstruction of Flow
}

National Cancer Institute

\section{Source}

National Cancer Institute. Obstruction of Flow. NCI Thesaurus. Code C62897.

Problem related to an obstruction or blockage within the device component (e.g. tube, opening, pipe) that results in restriction of flow. 